\title{
Red Ambiental Interuniversitaria: hacia la institucionalización del compromiso ambiental en las universidades
}

En los últimos años, ha sido común escuchar sobre crisis ambiental, deterioro del ambiente o conflictos socioambientales, temas que han amenazado en diversos momentos a nuestro país. En paralelo, hay una tendencia de pensamiento ético en las universidades en la reflexión sobre la responsabilidad social, que involucra distintas áreas, y sobre su incorporación transversal en el quehacer de la educación superior. 


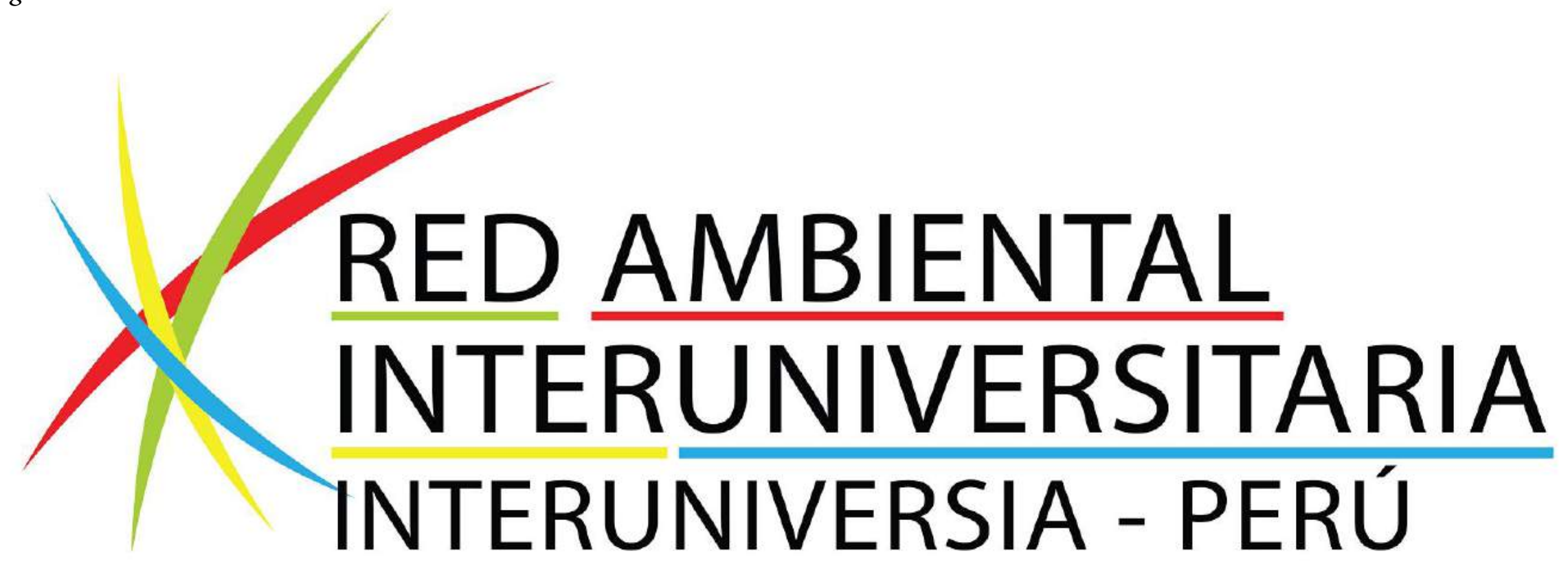

Fuente: Alianza de Redes Iberoamericanas de Universidades por la Sustentabilidad y el Ambiente (Ariusa)

E universidad es fortalecer la responsabilidad con un presente y futuro en los que predomine el reconomiento $\mathrm{y}$ vínculo entre los seres humanos $y$ el ambiente, generar conciencia del peligro que las prácticas humanas han causado al planeta y fortalecer el compromiso con una nueva forma de actuar respecto a nuestro entorno. Incorporar al discurso sobre la responsabilidad la preocupación por entender y responder a las problemáticas ambientales nos incumbe a todos, y la universidad no puede estar exenta a este llamado.

Las universidades, en concordancia con su misión, deben contribuir a formar profesionales que, desde distintas disciplinas y ámbitos del quehacer académico, sean un efectivo aporte a la sostenibilidad. Para lograrlo se requiere forjar un nuevo perfil de profesionales que retomen la tradición universitaria de contribuir al desarrollo del país aportando respuestas a las necesidades de la sociedad, entre ellas, al logro de una conciencia colectiva comprometida con el cuidado del ambiente.
En correspondencia con lo mencionado, en el Perú, desde 2012, se viene impulsando un proceso para convertir las universidades en ejemplos de responsabilidad ambiental promoviendo la institucionalización de este compromiso en las instituciones de educación superior a través de la incorporación de la dimensión ambiental en las diversas funciones sustantivas de las universidades (gestión, formación, investigación, y proyección social y extensión universitaria). La institucionalización del compromiso ambiental implica pasar de una situación donde se considera esta dimensión como un agregado más que se imparte en las universidades o el patrimonio de una orientación profesional determinada hacia otra donde esté integrada en la propuesta institucional y se transversalice en la oferta formativa de todas las carreras universitarias, es decir, lo ambiental como sello del quehacer de la institución.

Uno de los mecanismos para promover la institucionalización del compromiso ambiental en la edu- cación superior ha sido la creación de la Red Ambiental Interuniversitaria Interuniversia - Perú (RAI). La RAI es una red de buena voluntad conformada por universidades públicas y privadas que aspiran a ser ejemplo de responsabilidad ambiental. Promueve la incorporación de la dimensión ambiental en las funciones sustantivas de la universidad, así como el aumento y la mejora de la participación de la comunidad universitaria en actividades dirigidas a la sostenibilidad ambiental dentro y fuera de sus campus. Actualmente, el Ministerio del Ambiente facilita esta red, que cuenta con la participación de 72 universidades.

La RAI también forma parte de otros movimientos regionales $y$ mundiales que abogan por el compromiso ambiental de las universidades. Tal es el caso de la Alianza de Redes Iberoamericanas de Universidades por la Sustentabilidad $y$ el Ambiente (Ariusa) y la Alianza Mundial de Universidades Sobre Ambiente y Sostenibilidad (Gupes). 
Figura 2. La Red Ambiental Interuniversitaria agrupa a universidades de todas las regiones del país

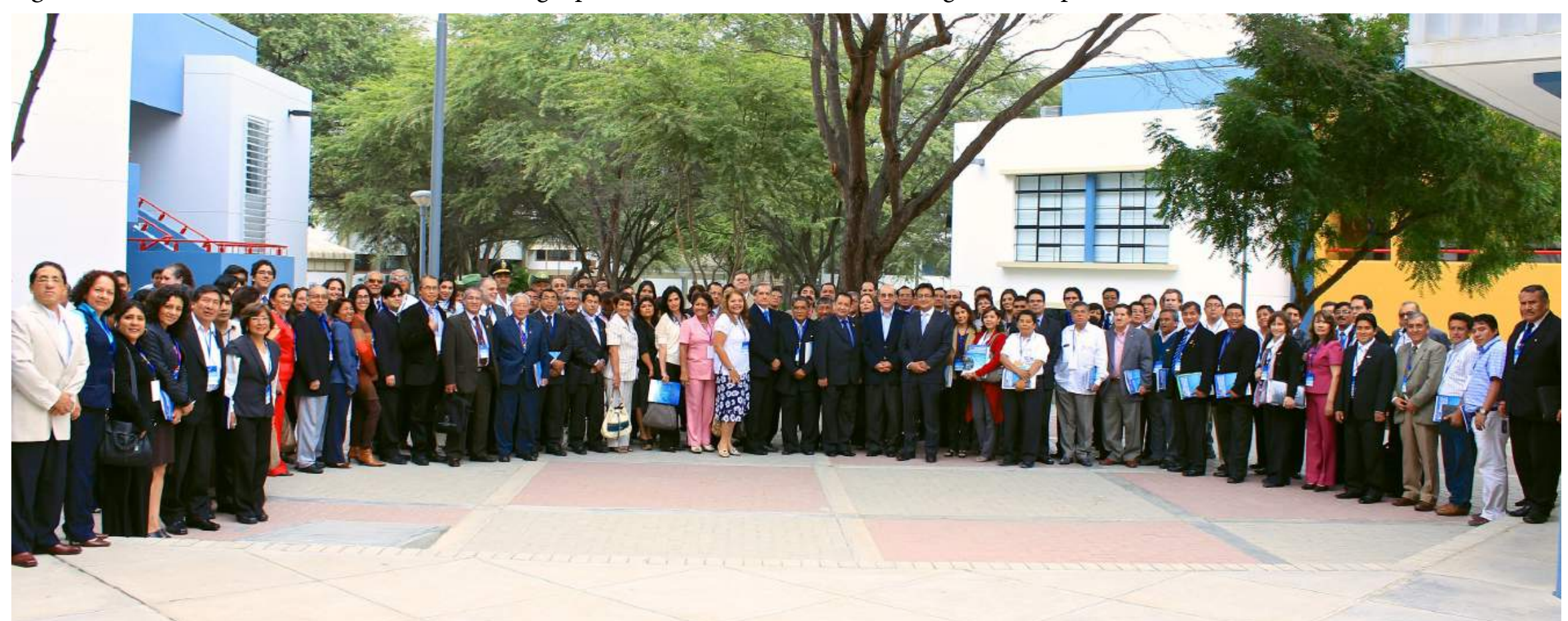

Fuente: Dgecca- Minam

Figura 3. Los Foros Nacionales de Universidades, Gestión Ambiental y Desarrollo Sostenible, principales espacios de encuentro y debate de la Red Ambiental Interuniversitaria

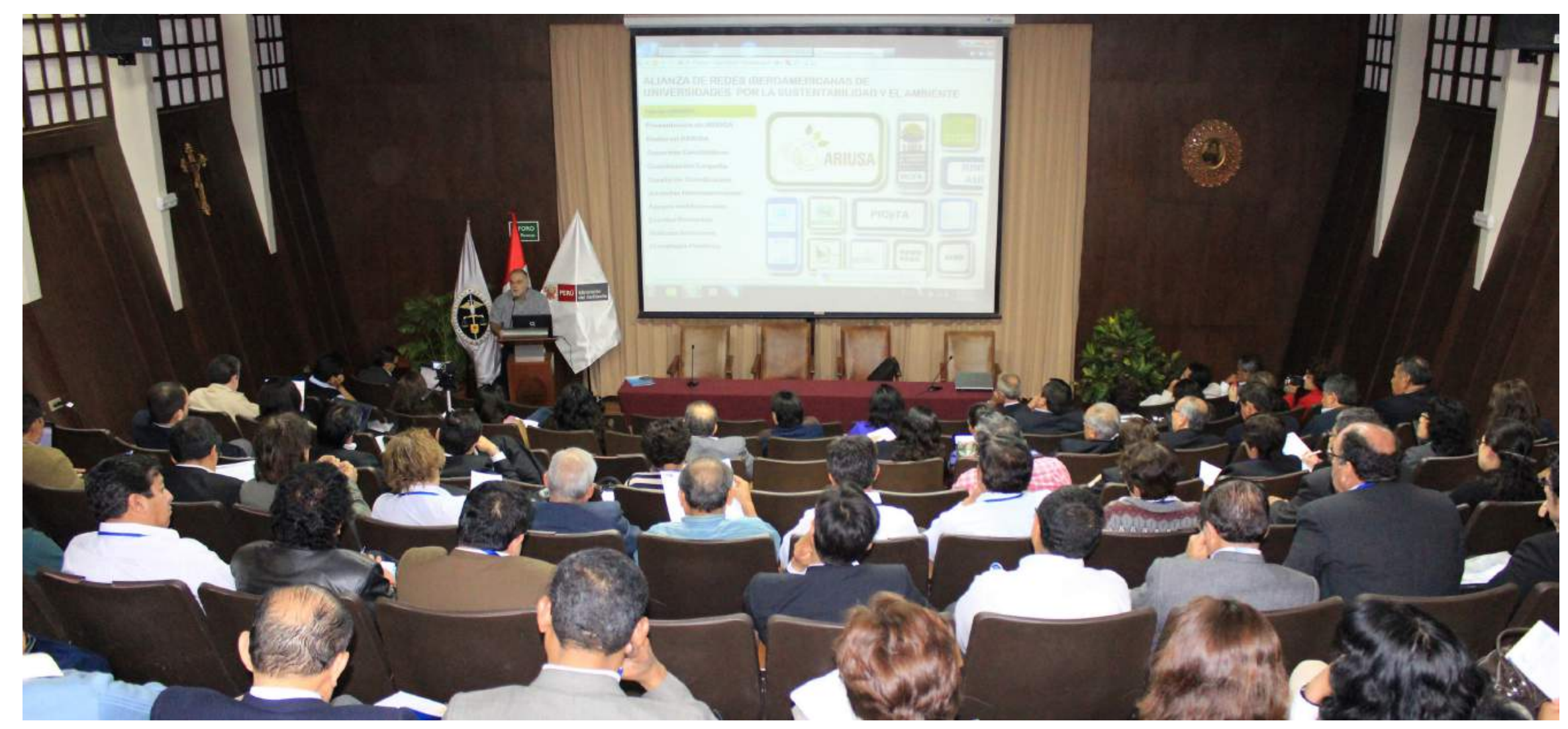

Fuente: Dgecca - Minam

La RAI está conformada por universidades públicas y privadas

que aspiran a ser ejemplo de responsabilidad ambiental. 
Entre las actividades que realiza, se encuentran la organización de foros, encuentros y seminarios sobre responsabilidad ambiental universitaria; la difusión de prácticas y experiencias ejemplares; el intercambio de experiencias entre universidades; la difusión de eventos nacionales $e$ internacionales sobre universidad y ambiente; la difusión de documentos (guías, manuales, libros, publicaciones en revistas) vinculados al tema; el monitoreo y la difusión de reportes ambientales de universidades, entre otras.

Desde que se comenzó a promover la institucionalización del compromiso ambiental en las universidades del Perú, se observan diversos avances. Cada vez, y en mayor medida, el tema del cuidado medioambiental es considerado en el discurso y la práctica universi- tarios. Se han formulado políticas ambientales en diversas instituciones, se han constituido comités ambientales universitarios, se han incorporado cursos y contenidos sobre medio ambiente en los planes de estudio de diversas carreras profesionales, entre otros; $y$, sobre todo, varias universidades están comprendiendo que la evaluación de la calidad de la propuesta formativa que ofrecen debe incorporar el discurso de la sostenibilidad ambiental.

Figura 4. La institucionalización del compromiso ambiental trasciende todos los ámbitos del quehacer universitario

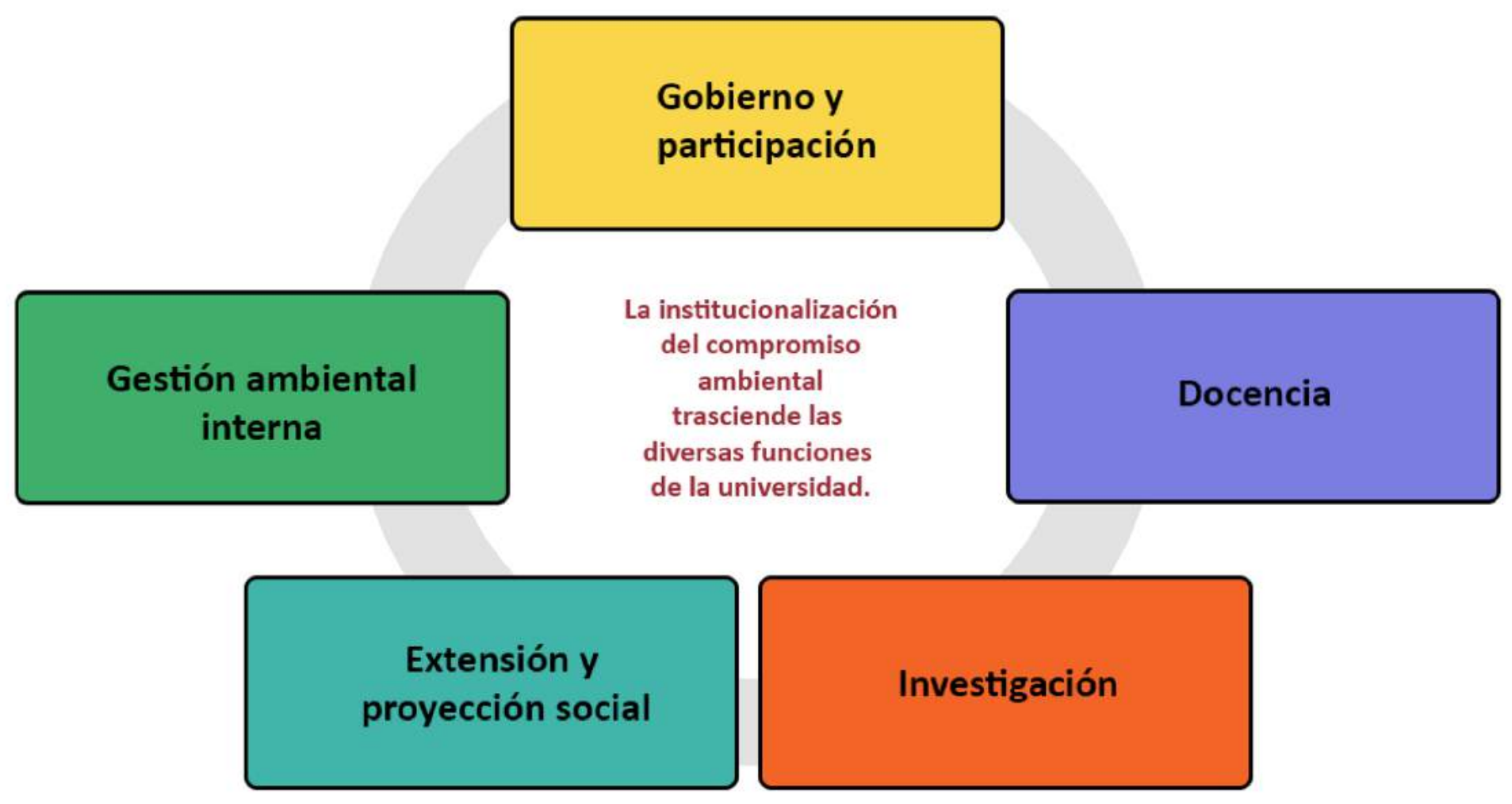

Fuente: Red Ambiental Interuniversitaria

La RAI promueve la incorporación de la dimensión ambiental en las funciones sustantivas de la universidad, así como el aumento y la mejora de la participación de la comunidad universitaria en actividades dirigidas a la sostenibilidad ambiental dentro y fuera de sus campus. 


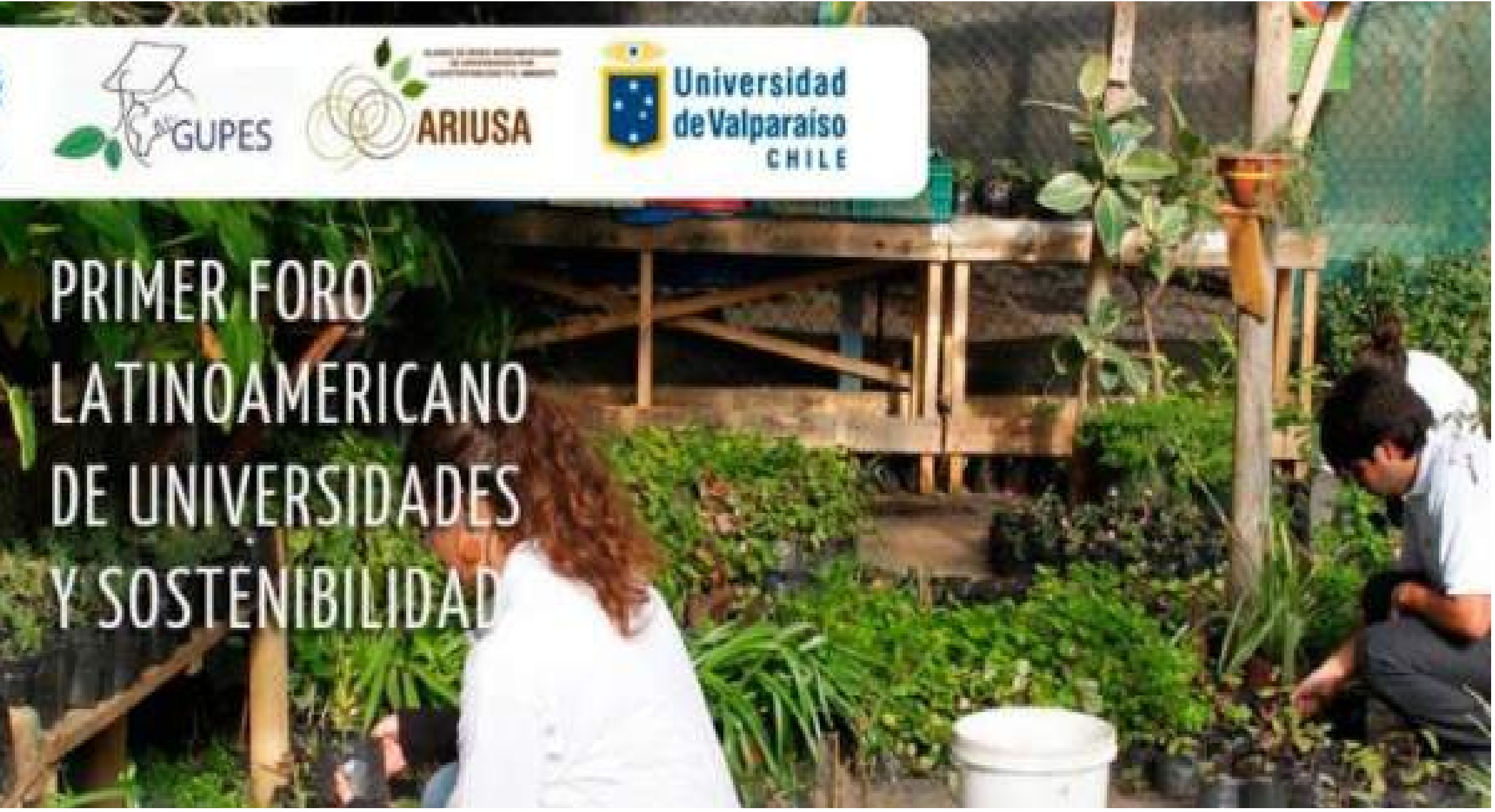

Fuente: Alianza de Redes Iberoamericanas de Universidades por la Sustentabilidad y el Ambiente (Ariusa)

Figura 6. Se realizó en Perú el V Foro Nacional de Universidades

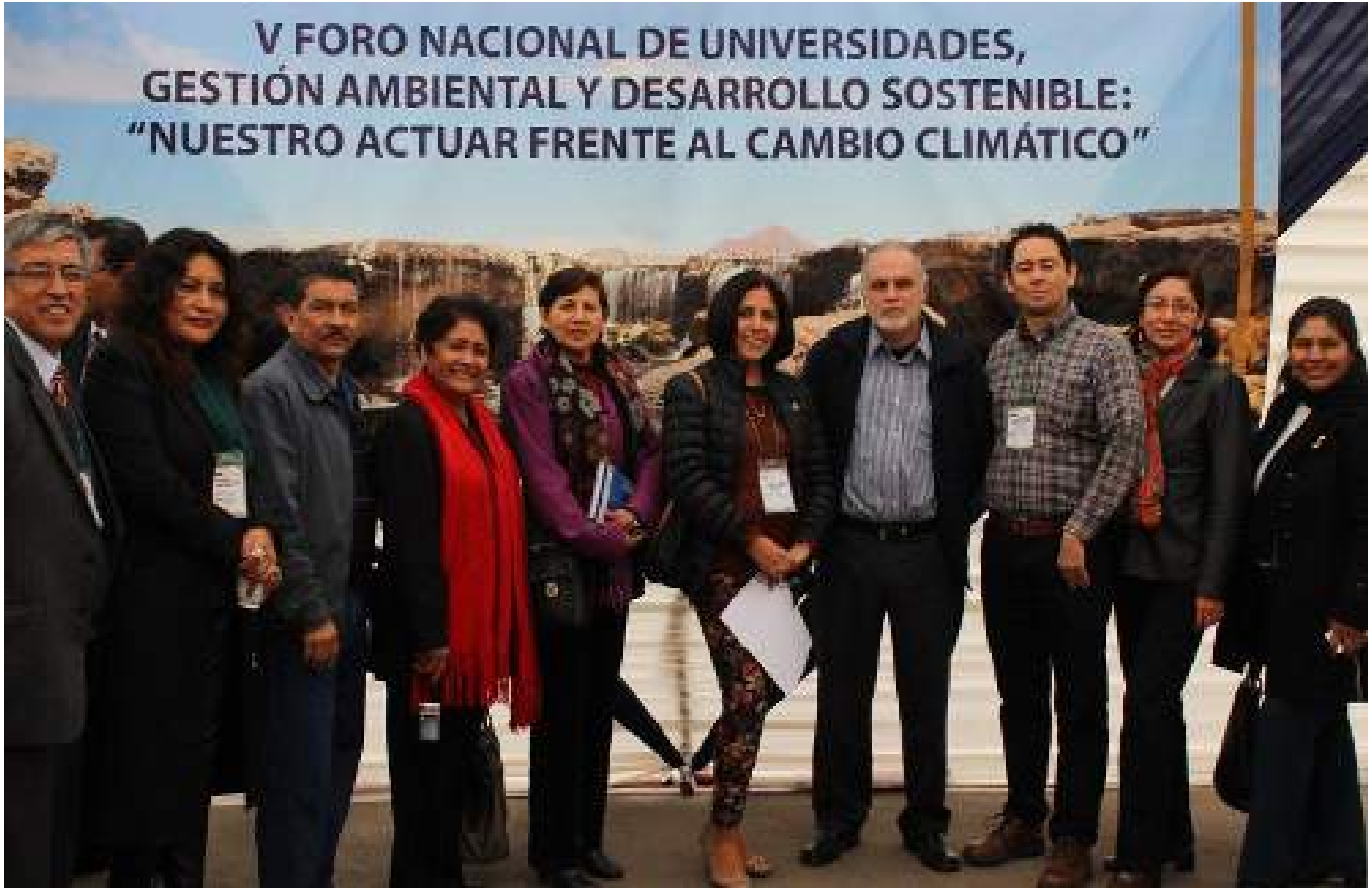

Fuente: Alianza de Redes Iberoamericanas de Universidades por la Sustentabilidad y el Ambiente (Ariusa) 